Supporting Information

\title{
From Theory to Experiment: Cascading of Thermocatalysis and Electrolysis in
}

\section{Oxygen Evolution Reactions}

Xing Fan, ${ }^{\ddagger a}$ Siyu Tan, ${ }^{\ddagger a}$ Junjun Yang, ${ }^{\mathrm{a}}$ Y unxia Liu, ${ }^{\mathrm{a}}$ Wenyi Bian, ${ }^{\mathrm{a}}$ Fan Liao, ${ }^{* a}$ Haiping Lin, ${ }^{\text {b }}$ and

Youyong $\mathrm{Li}^{* \mathrm{a}, \mathrm{c}}$

anstitute of Functional Nano \& Soft Materials (FUNSOM), Jiangsu Key Laboratory for Carbon-

Based Functional Materials \& Devices, Soochow University, Suzhou, Jiangsu 215123, China.

bSchool of Physics and Information Technology, Shaanxi Normal University, Xi'an, Shaanxi

710119, PR China.

${ }^{c}$ Macao Institute of Materials Science and Engineering, Macau University of Science and Technology, Taipa, 999078, Macau SAR, China

These authors contributed equally.

${ }^{*}$ Corresponding authors. 
E-mail: fliao@suda.edu.cn, hplin@snnu.edu.cn and yyli@suda.edu.cn.

\section{Computational Details and Experimental Methods}

\section{DFT calculations.}

Spin-polarized density functional theory (DFT) calculations Fe-BHT monolayer catalysed

OER were performed using Vienna ab initio simulation packages (VASP), version 5.4.1.1,2 The

ion-electron interaction was described with the projector augmented wave (PAW)

pseudopotential. ${ }^{3,4}$ The GGA functional proposed by Perdew-Burke-Ernzerhof $(\mathrm{PBE})^{5,}{ }^{6}$ was

used to calculate the exchange-correlation interactions between electrons. The cut-off energy of

the plane wave was set to $500 \mathrm{eV}$. The k-point sampling of the Brillouin zone was sampled by a

$6 \times 6 \times 1$ Monkhorst-Pack grid. The criterion of energy convergence was $1 \times 10^{-4} \mathrm{eV}$. The internal

coordinates of each system were fully optimized until the residual Hellmann-Feynman forces

were smaller than $0.01 \mathrm{eV} / \AA$ per atom. A vacuum of $20 \AA$ in the $\mathrm{z}$ direction was employed to 
avoid the interactions between periodic images. The vdW contributions in local chemical environment were evaluated with the DFT-D3 method. ${ }^{7}$ The transition states (TS) in calculated thermocatalytic processes and the corresponding kinetic barriers were obtained by the climbingimage nudged elastic band (CI-NEB) method. ${ }^{8}$

The four elementary steps of OER in acidic conditions are described by Equations (1)-(4): ${ }^{9}$

$$
\begin{gathered}
\mathrm{H}_{2} \mathrm{O}+* \rightarrow \mathrm{OH}^{*}+\mathrm{H}^{+}+\mathrm{e}^{-\#(1)} \\
\mathrm{OH}^{*} \rightarrow \mathrm{O}^{*}+\mathrm{H}^{+}+\mathrm{e}^{-} \#(2) \\
\mathrm{O}^{*}+\mathrm{H}_{2} \mathrm{O} \rightarrow \mathrm{OOH}^{*}+\mathrm{H}^{+}+\mathrm{e}^{-\#(3)} \\
\mathrm{OOH}^{*} \rightarrow \mathrm{O}_{2}+\mathrm{H}^{+}+\mathrm{e}^{-\#(4)}
\end{gathered}
$$

with the asterisk (*) in the equations denotes an active site to the surface. The computational hydrogen electrode(CHE) method was used to account for the Gibbs free energy change $(\Delta \mathrm{G})$ for each elementary step, ${ }^{10}$ which is calculated as follows:

$$
\Delta \mathrm{G}=\Delta \mathrm{E}+\Delta \mathrm{ZPE}-\mathrm{T} \Delta \mathrm{S}+\Delta G_{p H}+\Delta G_{U}
$$

where $\Delta \mathrm{E}$ is the electronic energy difference of product and reactant for each elementary step, $\triangle \mathrm{ZPE}$ is the difference in zero point energy that can be calculated by $\Delta \mathrm{ZPE}=\frac{1}{2} h v$ where $\mathrm{v}$ is the vibrational frequency of a normal mode and $\mathrm{h}$ is the Planck constant. And $\Delta \mathrm{S}$ is the difference in entropy that can be calculated by the equation: ${ }^{11}$ 


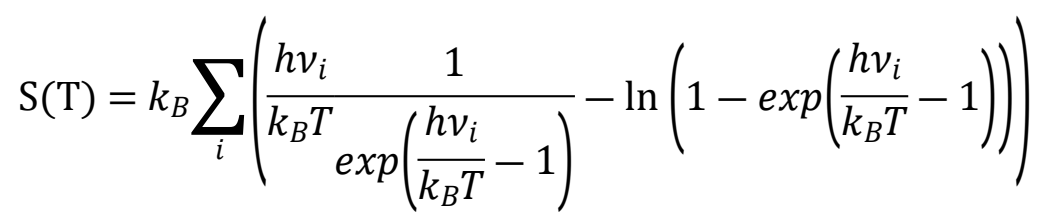

where $k_{B}$ and $v_{i}$ are referred to as Boltzmann's constant and vibrational frequency, respectively.

The temperature (T) is set to be $298.15 \mathrm{~K} . \Delta G_{p H}=k_{B} T \ln 10 \times p H$ is the free energy contributions related to the $\mathrm{H}^{+}$concentration. $\Delta G_{U}=+\mathrm{eU}$, where e is the number of electrons involved and $\mathrm{U}$ is the applied electrode bias. The Helmholtz free energy, zero-point energy and entropy of isolated and adsorbed species are listed in Table S1. The theoretical overpotential $\eta$ obtained from Gibbs free energy differences $\Delta \mathrm{G}_{\mathrm{x}}(\mathrm{x}=1, \ldots, 4)$ at each elementary step can be written as:

$$
\eta=\frac{\max \left[\Delta G_{1}, \Delta G_{2}, \Delta G_{3}, \Delta G_{4}\right]}{e}-1.23[V]
$$

\section{Calculations of Temperature effects on standard OER potentials.}

The standard OER potential changes slightly when reaction temperature changes. However, to the best of our knowledge, this function is not clearly reported in previous experimental measurements. Therefore, in this work, the overpotentials shown in Figure 4 are calculated by considering OER standard potential is $1.23 \mathrm{~V}$ for all temperatures. The standard OER potentials 
at different reaction temperatures $\left(\mathrm{T}=293.15 \mathrm{~K}\right.$ to $353.15 \mathrm{~K}$, that is, $20{ }^{\circ} \mathrm{C}$ to $\left.80{ }^{\circ} \mathrm{C}\right)$ are calculated by the recently advanced framework by Emily and colleagues as a reference here, which are described by equations as follows. ${ }^{12}$ In this framework, the Gibbs free energies of molecular species at temperature $\mathrm{T}(\mathrm{K})$ lower than the boiling point of water are calculated as follows:

$$
G_{i}^{0}(T)=E_{i}+Z P E_{i}+\left[H_{i}^{0}(T)-H_{i}^{0}(0 K)-T S_{i}^{0}(T)\right]
$$

where i denotes $\mathrm{H}_{2}(\mathrm{~g})$ or $\mathrm{H}_{2} \mathrm{O}(\mathrm{g})$, and $H_{i}{ }^{0}(T)$ and $S_{i}^{0}(T)$ are its standard enthalpy and entropy at T, respectively, which are calculated by the Shomate equations from the National Institute of Standards and Technology (NIST) database: ${ }^{13}$

$$
\begin{gathered}
H_{i}^{0}(T)-H_{i}^{0}(298.15 K)=A_{i} t+\frac{B_{i} t^{2}}{2}+\frac{C_{i} t^{3}}{3}+\frac{D_{i} t^{4}}{4}-\frac{E_{i}}{t}+F_{i}-H^{\prime}{ }_{i} \\
S_{i}^{0}(T)=A_{i} \ln t+B_{i} t+\frac{C_{i} t^{2}}{2}+\frac{D_{i} t^{3}}{3}-\frac{E_{i}}{2 t^{2}}+G_{i}
\end{gathered}
$$

where $t=T[\mathrm{~K}] / 1000$, and $A_{i}$ to $G_{i}$ are experimentally derived constants for each molecular species i (Tables S3). The values of $H_{i}^{0}(298.15 K)-H_{i}^{0}(0 K)$ for $\mathrm{H}_{2}$ and $\mathrm{H}_{2} \mathrm{O}$ are obtained from the NIST database. The standard Gibbs free energy of $\mathrm{H}_{2} \mathrm{O}(\mathrm{l})$ at temperature $\mathrm{T}$ are obtained as: 


$$
\begin{aligned}
G_{\mathrm{H}_{2} \mathrm{O}(l)}^{0}(T) & \\
& =G_{\mathrm{H}_{2} \mathrm{O}(g)}^{0}(T)+\Delta G_{c, \mathrm{H}_{2} \mathrm{O}}^{0}(298.15 K)+\left[\Delta G_{\mathrm{H}_{2} \mathrm{O}(l)}^{0}(298.15 K \rightarrow T)-\Delta G_{\mathrm{H}_{2} \mathrm{O}(g)}^{0}\right. \\
& (298.15 K \rightarrow T)]
\end{aligned}
$$

where $\Delta G_{\mathrm{c}, \mathrm{H}_{2} \mathrm{O}}^{0}(298 \mathrm{~K})$ is the Gibbs free energy of the condensation of $\mathrm{H}_{2} \mathrm{O}(\mathrm{g})$ at $298.15 \mathrm{~K}$

obtained from the NIST database. And $\Delta G_{\mathrm{i}}^{0}(298.15 K \rightarrow T)$ denotes the change of the standard

Gibbs free energy in changing the temperature of species i from $298.15 \mathrm{~K}$ to $\mathrm{T}$.

The Gibbs free energy of $\mathrm{O}_{2}(\mathrm{~g})$ at temperature $\mathrm{T}$ is calculated as:

$$
G_{\mathrm{O}_{2}(\mathrm{~g})}^{0}(T)=\Delta G_{\mathrm{r}, \mathrm{H}_{2} \mathrm{O}_{\text {split }}}^{0}(T)+\left[2 G_{\mathrm{H}_{2} \mathrm{O}(\mathrm{l})}^{0}(T)-2 G_{\mathrm{H}_{2}(\mathrm{~g})}^{0}(T)\right]
$$

where $\Delta G_{\mathrm{r}, \mathrm{H}_{2} \mathrm{O}_{\text {split }}}(T)$ denotes the standard Gibbs free energy of the reaction for water splitting at temperature $\mathrm{T}$, which can be obtained by:

$$
\Delta G_{\mathrm{r}, \mathrm{H}_{2} \mathrm{O}_{\text {split }}}^{0}(T)=-2 \Delta G_{\mathrm{f}, \mathrm{H}_{2} \mathrm{O}(\mathrm{l})}^{0}(T)
$$

where $\Delta G_{f, \mathrm{H}_{2} \mathrm{O}(\mathrm{l})}^{0}(T)$ denotes the standard free energy of the formation of $\mathrm{H}_{2} \mathrm{O}(1)$, which has been estimated as follows:

$\Delta G_{\mathrm{f}, \mathrm{H}_{2} \mathrm{O}(\mathrm{l})}^{0}(T)=\Delta G_{\mathrm{f}, \mathrm{H}_{2} \mathrm{O}(\mathrm{l})}^{0}(298.15 K)+$ $\left(\Delta G_{\mathrm{H}_{2} \mathrm{O}(\mathrm{l})}^{0}(298.15 K \rightarrow T)-\Delta G_{\mathrm{H}_{2}(\mathrm{~g})}^{0}(298.15 K \rightarrow T)-\frac{1}{2} \Delta G_{\mathrm{O}_{2}(g)}^{0}(298.15 K \rightarrow T)\right)$

where $\Delta G_{\mathrm{f}, \mathrm{H}_{2} \mathrm{O}(\mathrm{l})}^{0}(298.15 K)$ is obtained from the NIST database and the values of $\Delta G_{\mathrm{i}}^{0}$ $(298.15 K \rightarrow T)$ are calculated using the respective Shomate equation with constants in Tables S3.

Based on the equations above, we plot the calculated standard Gibbs free energies $G_{i}^{0}(T)$ of 
$\mathrm{O}_{2}(\mathrm{~g}), \mathrm{H}_{2}(\mathrm{~g})$ and $\mathrm{H}_{2} \mathrm{O}(\mathrm{l})$ as functions of temperature from $293.15 \mathrm{~K}$ to $353.15 \mathrm{~K}\left(20{ }^{\circ} \mathrm{C}\right.$ to $\left.80{ }^{\circ} \mathrm{C}\right)$ in Figure S8, which shows different slopes.

And the standard Gibbs free energy of the OER equals exactly the standard Gibbs free energy of water splitting:

$$
\Delta G_{\mathrm{r}, \mathrm{OER}}^{0}(T)=\Delta G_{\mathrm{r}, \mathrm{H}_{2} \mathrm{O}_{\text {split }}}^{0}(T)
$$

Thus, the standard potential of the OER $\left(E_{\mathrm{OER}}^{0}\right)$ is estimated by

$$
E_{\mathrm{OER}}^{0}=\frac{\Delta G_{\mathrm{r}, \mathrm{OER}}^{0}(T)}{4 e}=\frac{-\Delta G_{\mathrm{f}, \mathrm{H}_{2} \mathrm{O}(\mathrm{l})}^{0}(T)}{2 e}
$$

Accordingly, we plot the standard reduction potential of the OER ( $\left.\mathrm{E}_{\mathrm{OER}}^{0}\right)$ measured versus the RHE as a function of temperature in Figure S9. The calculated standard OER potentials at 20 ${ }^{\circ} \mathrm{C}, 40{ }^{\circ} \mathrm{C}, 60{ }^{\circ} \mathrm{C}$ and $80{ }^{\circ} \mathrm{C}$ are $1.233 \mathrm{~V}, 1.216 \mathrm{~V}, 1.200 \mathrm{~V}$ and $1.183 \mathrm{~V}$ (Figure S9), respectively. Therefore, the overpotentials shown in Figure 4 should be slightly larger by considering temperature effects on standard OER potentials. Since experimental measurements of quantitative temperature effects for OER potentials are not published, theoretical corrections shown in Figure S9 are employed to mimic the temperature effects on the measured overpotentials (see Figure S10). As seen, the overpotentials at $40{ }^{\circ} \mathrm{C}, 60{ }^{\circ} \mathrm{C}$ and $80{ }^{\circ} \mathrm{C}$ shown in Figure 4(f) are increased by considering temperature effects on standard OER potentials. However, the relative performance between $\mathrm{IrO}_{2}$ and $\mathrm{Fe}-\mathrm{BHT}$ is not changed, indicating that FeBHT outperforms $\mathrm{IrO}_{2}$ at around $80{ }^{\circ} \mathrm{C}$ is still valid.

\section{Synthesis of Fe-BHT nanocrystals.}


BHT was purchased from Shanghai Macklin Biochemical Co. The Fe-BHT nanocrystal was prepared in argon atmosphere. In detail, $1.5 \mathrm{mg} \mathrm{FeCl} 2$ was dissolved in $50 \mathrm{~mL}$ degassed ethanol. Subsequently, $50 \mathrm{mg}$ of the BHT powders were slowly added to the solution. The reaction proceeded at room temperature for $1 \mathrm{~h}$. A dark purple deposit was synthesized and collected. Finally, the product was washed with water, ethanol and acetone and dried by lyophilisation.

\section{Characterizations.}

The morphology of Fe-BHT nanocrystals was measured by scanning electron microscope (SEM, Zeiss Supra 55 with accelerating voltage of $5 \mathrm{KV}$ ). X-ray powder diffraction (XRD) pattern was collected on the Philips X'pert PRO MPD diffractometer equipped with $\mathrm{Cu} \mathrm{K} \alpha$ radiation $(\lambda=0.15406 \mathrm{~nm})$.

\section{Electrochemical Measurement.}

All electrochemical measurements were carried out in a standard three-electrode cell system

using a CHI-760E electrochemical workstation, where a $\mathrm{Ag} / \mathrm{AgCl}$ electrode and a graphite rod were selected as the reference electrode and the counter electrode, respectively. The $\mathrm{Ag} / \mathrm{AgCl}$ reference electrode is calibrated by temperature through the equation of $E_{\mathrm{T}}(\mathrm{V})$ $=0.199-0.00101 \times\left(\mathrm{T}\left({ }^{\circ} \mathrm{C}\right)-25^{\circ} \mathrm{C}\right)$, where $\mathrm{E}_{\mathrm{T}}$ is the calibrated potential of $\mathrm{Ag} / \mathrm{AgCl}$

reference electrode vs. RHE and T is the reaction temperature. ${ }^{14,15}$ Correspondingly, the standard electrode potentials of $\mathrm{Ag} / \mathrm{AgCl}$ vs. $\mathrm{RHE}$ at $20{ }^{\circ} \mathrm{C}, 40{ }^{\circ} \mathrm{C}, 60{ }^{\circ} \mathrm{C}$ and $80{ }^{\circ} \mathrm{C}$ are $0.204 \mathrm{~V}, 0.184 \mathrm{~V}$, 
$0.164 \mathrm{~V}$ and $0.143 \mathrm{~V}$, respectively. All tests were measured in $1.0 \mathrm{M} \mathrm{KOH}$ solution, and the potential was normalized to RHE according to the equation of $\mathrm{E}(\mathrm{vs} \cdot \mathrm{RHE})=\mathrm{E}(\mathrm{vs} \cdot \mathrm{Ag} / \mathrm{AgCl})+\mathrm{E}_{\mathrm{T}}$ $+\mathrm{pH} \times 0.0591 \mathrm{~V}$. All linear sweep voltammetry $(\mathrm{LSV})$ curves are treated by $95 \%$ iRcompensation. The catalytic activity tests have the same loading and the same heat treatment time. The geometrical area of the glassy carbon electrode, on which the catalysts were loaded, was calculated to be $0.0707 \mathrm{~cm}^{2}$. This value was used to determine the current density in the LSV curves.

To prepare the working electrode, $4.0 \mathrm{mg}$ of the synthesized Fe-BHT catalysts or commercial $\mathrm{IrO}_{2}$ were sonicated in a mixed solution composed of $0.75 \mathrm{~mL}$ water, $0.15 \mathrm{~mL}$ isopropanol and $0.1 \mathrm{~mL}$ Nafion $(0.5 \mathrm{wt} \%)$ to ensure a good dispersion. Then, $4.0 \mu \mathrm{L}$ of the suspension was dipped on the glassy carbon electrode. Electrochemical impedance spectroscopy (EIS) was carried out with the frequency ranging from $100 \mathrm{kHz}$ to $0.1 \mathrm{~Hz}$.

Table S1. The calculated electronic energy, ZPE, entropy, and free energy of molecules and intermediate states in OER at $0.00 \mathrm{~V}$.

\section{Species}




\begin{tabular}{ccccc}
\hline & $(\mathrm{eV})$ & $(\mathrm{eV})$ & $(\mathrm{eV})$ & $(\mathrm{eV})$ \\
\hline Molecules & & & & \\
$\mathrm{H}_{2}$ & -6.75 & 0.28 & 0.07 & -6.54 \\
$\mathrm{H}_{2} \mathrm{O}$ & -14.21 & 0.57 & 0.33 & -13.98 \\
Intermediate states & & & & \\
Fe-BHT & -104.64 & 0.10 & 0.14 & -104.68 \\
$\mathrm{HO}-\mathrm{Fe}-\mathrm{BHT}$ & -114.99 & 0.41 & 0.27 & -114.86 \\
O-Fe-BHT & -110.49 & 0.16 & 0.23 & -110.56 \\
O-Fe-HO-S & -120.13 & 0.51 & 0.28 & -119.90 \\
HOO-Fe-BHT & -119.34 & 0.51 & 0.32 & -119.16 \\
O-Fe-BHT & -115.15 & 0.19 & 0.24 & -115.20 \\
HO-Fe-HO-S & -124.42 & 0.77 & 0.36 & -124.02 \\
HO-Fe-O-S & -120.59 & 0.55 & 0.28 & -120.31 \\
\hline & & & & \\
\hline
\end{tabular}




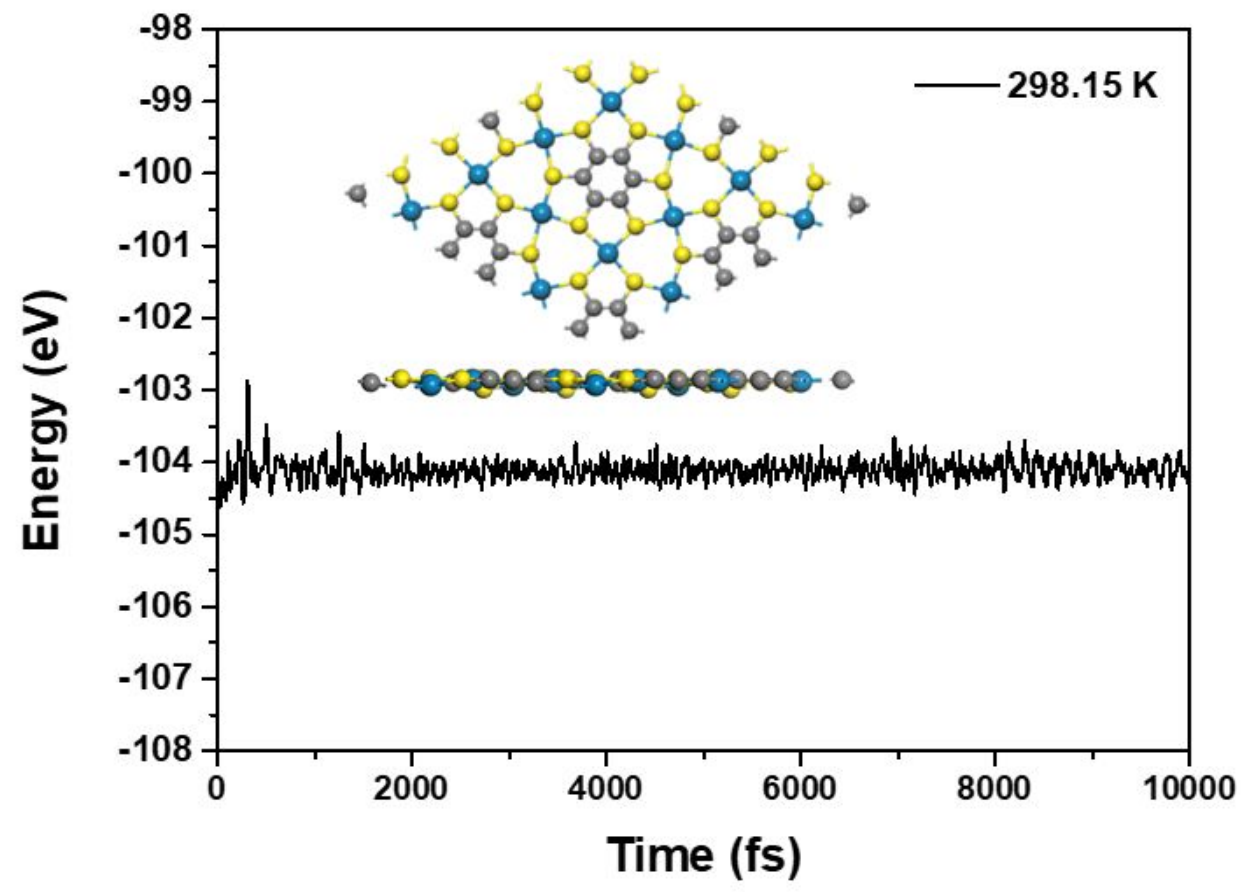

Figure S1. The AIMD simulation of Fe-BHT monolayer at 298.15K for 10000 fs. The inserted images are the top and side views of the final Fe-BHT structure at 298.15K.

Table S2. The Bader charge on the Fe atom $\left(\mathrm{Q}_{\mathrm{Fe}}\right)$ and the averaged Bader charge on each $\mathrm{S}$ atom $\left(\mathrm{Q}_{\mathrm{S}}\right)$ in a $\mathrm{FeS}_{4}$ motif.

\begin{tabular}{cccc}
\hline Catalyst & Fe-S distance $(\AA)$ & $\mathrm{Q}_{\mathrm{Fe}}(\mathrm{e})$ & $\mathrm{Q}_{\mathrm{S}}(\mathrm{e})$ \\
\hline Fe-BHT & 2.215 & +0.73 & -0.22 \\
\hline
\end{tabular}


(a) $\mathrm{Fe}^{*} \mathrm{O}$

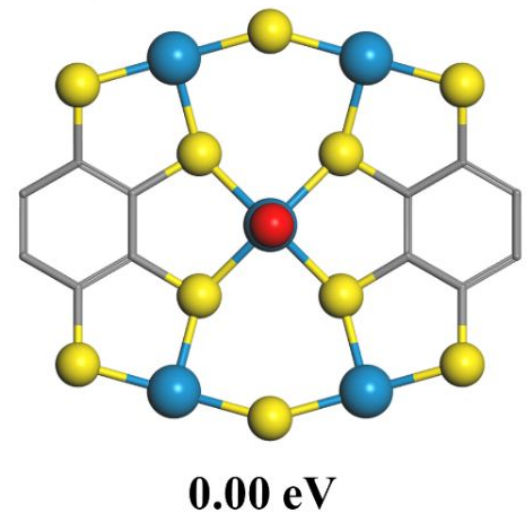

(b) $\mathrm{S} * \mathrm{O}$

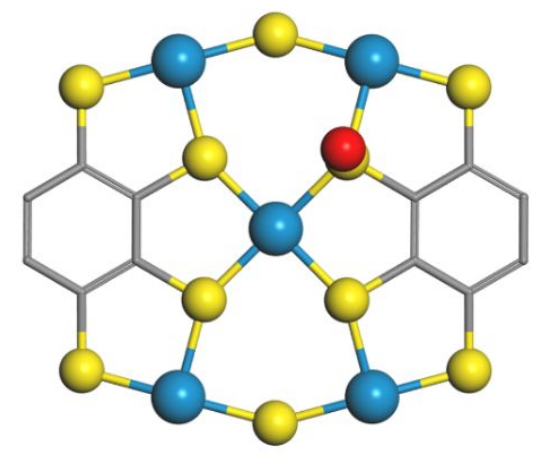

$0.60 \mathrm{eV}$

Figure S2. The adsorption of $* \mathrm{O}$ on (a) Fe and (b) $\mathrm{S}$ in a Fe-BHT monolayer and their relative energies.

(a) $\mathrm{Fe}^{*} \mathrm{O}_{2}$

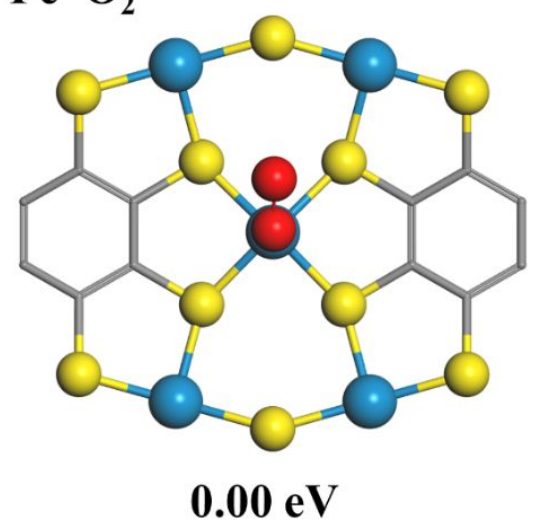

(b) $\mathrm{S}^{*} \mathrm{O}_{2}$

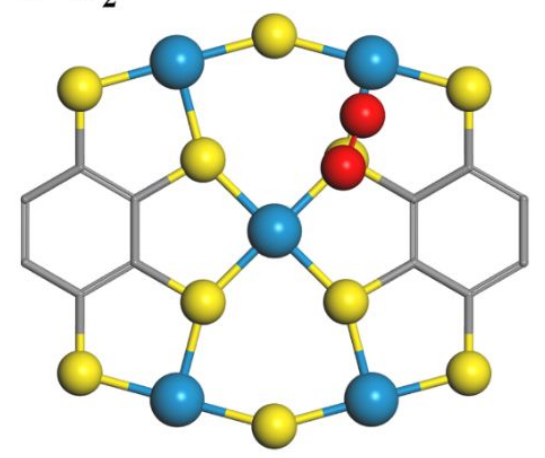

$0.70 \mathrm{eV}$

Figure S3. The adsorption of $* \mathrm{O}_{2}$ on (a) Fe and (b) $\mathrm{S}$ in a Fe-BHT monolayer and their relative energies. 
(a) $\mathrm{Fe}^{*} \mathrm{OH}$

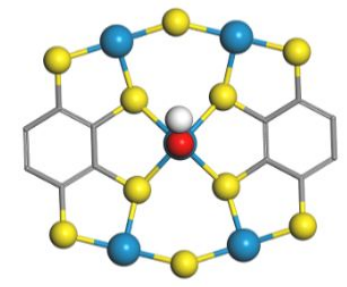

$0.00 \mathrm{eV}$ (b) $\mathrm{S} * \mathrm{OH}$

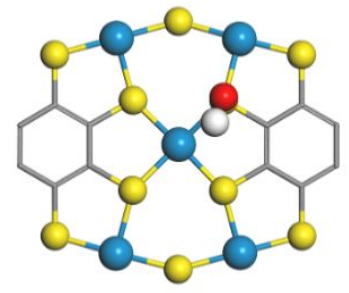

$1.34 \mathrm{eV}$ (c) $\mathrm{Fe}^{*} \mathrm{O}-\mathrm{S} * \mathrm{H}$

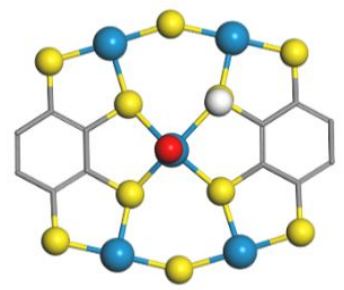

$1.83 \mathrm{eV}$

Figure S4. The adsorption configurations and relative energies of (a) $* \mathrm{OH}$ on $\mathrm{Fe},(\mathrm{b}) * \mathrm{OH}$ on $\mathrm{S}$,

(c) $* \mathrm{O}$ on $\mathrm{Fe}$ and $* \mathrm{H}$ on $\mathrm{S}$.

(a) $\mathrm{Fe}^{*} \mathrm{OH}-\mathrm{S} * \mathrm{O}$

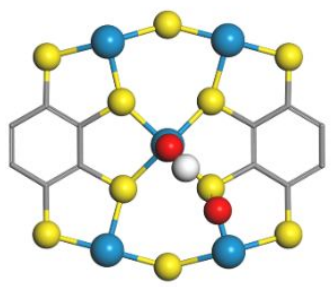

$0.00 \mathrm{eV}$ (b) $\mathrm{Fe}^{*} \mathrm{O}-\mathrm{S} * \mathrm{OH}$

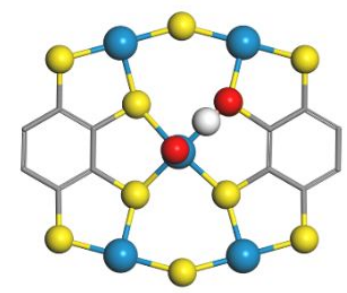

$0.46 \mathrm{eV}$ (c) $\mathrm{Fe}^{*} \mathrm{OOH}$

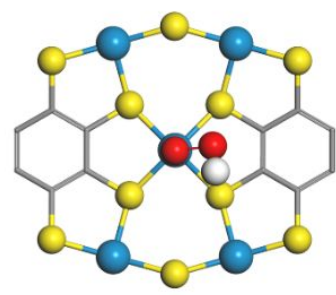

$1.25 \mathrm{eV}$

Figure S5. The adsorption configurations and relative energies of (a) *OH on $\mathrm{Fe}$ and $* \mathrm{O}$ on $\mathrm{S}$,

(b) $* \mathrm{O}$ on $\mathrm{Fe}$ and $* \mathrm{OH}$ on $\mathrm{S}$, (c) $* \mathrm{OOH}$ on $\mathrm{Fe}$. 


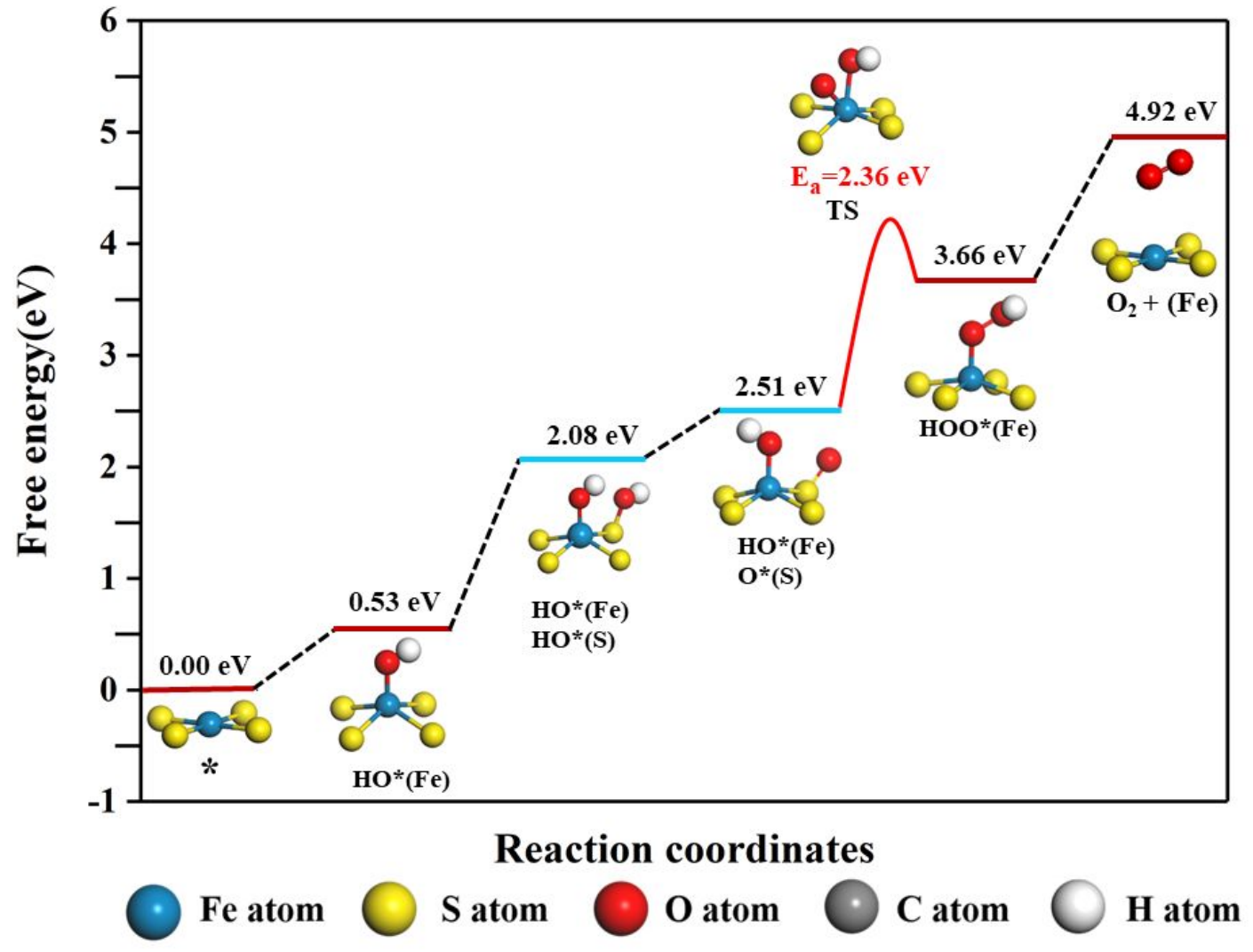

Figure S6. The energy profile of another possible thermally and electrically cascaded OER pathway on a Fe-BHT monolayer, respectively. 


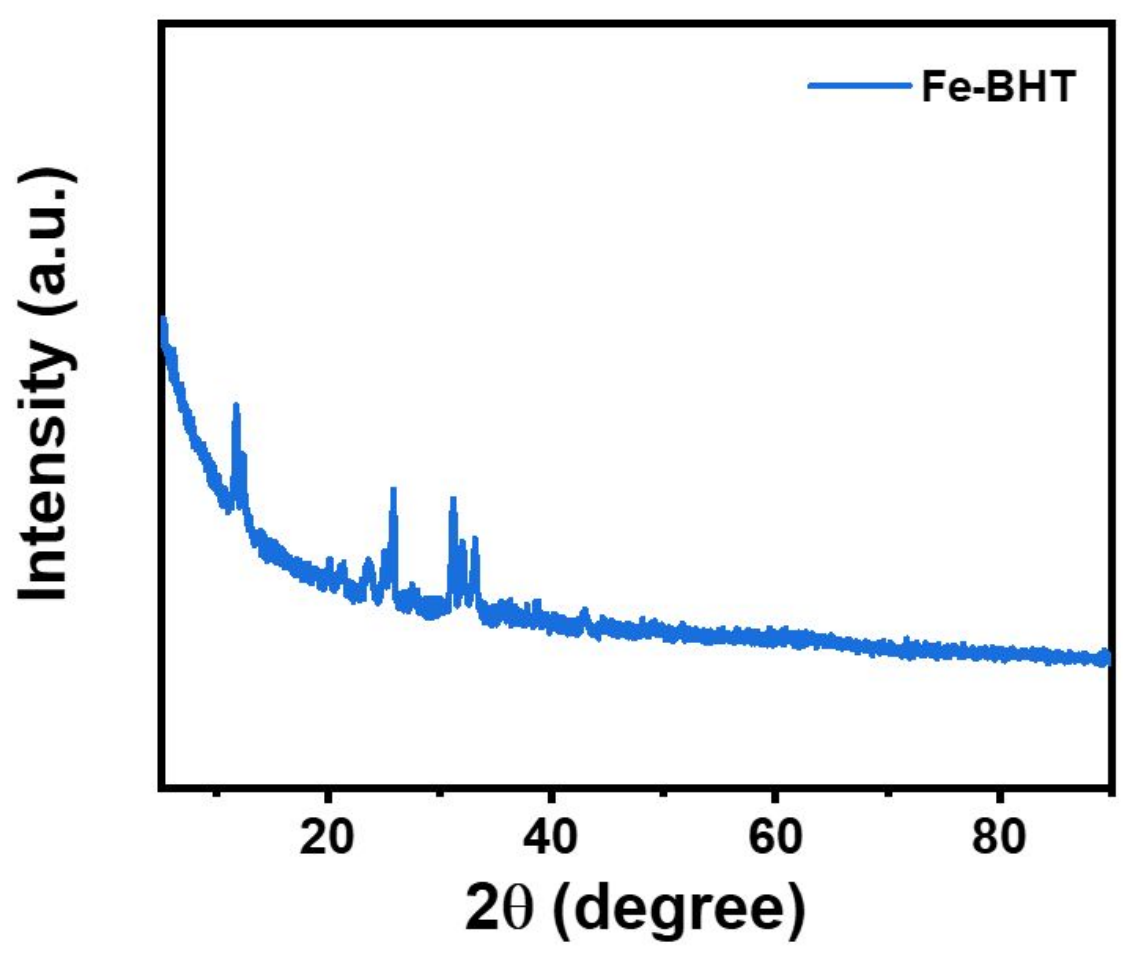

Figure S7. XRD pattern of Fe-BHT nanocrystals.

Table S3. The Shomate equation parameters for molecular species adapted from the NIST database. $^{13}$

\begin{tabular}{ccccc}
\hline Parameters & $\mathrm{H}_{2}(\mathrm{~g})$ & $\mathrm{H}_{2} \mathrm{O}(\mathrm{g})$ & $\mathrm{H}_{2} \mathrm{O}(\mathrm{l})$ & $\mathrm{O}_{2}(\mathrm{~g})$ \\
\hline $\mathrm{A}$ & 33.066178 & 30.09200 & -203.6060 & 31.32234 \\
$\mathrm{~B}$ & -11.363417 & 6.832514 & 1523.290 & -20.23531 \\
$\mathrm{C}$ & 11.432816 & 6.793435 & -3196.413 & 57.86644 \\
D & -2.772874 & -2.534480 & 2474.455 & -36.50624 \\
E & -0.158558 & 0.082139 & 3.855326 & -0.007374 \\
\hline
\end{tabular}




\begin{tabular}{ccccc}
\hline F & -9.980797 & -250.8810 & -256.5478 & -8.903471 \\
G & 172.707974 & 223.3967 & -488.7163 & 246.7945 \\
$H^{\prime}$ & 0.0 & -241.8264 & -285.8304 & 0.0 \\
\hline
\end{tabular}

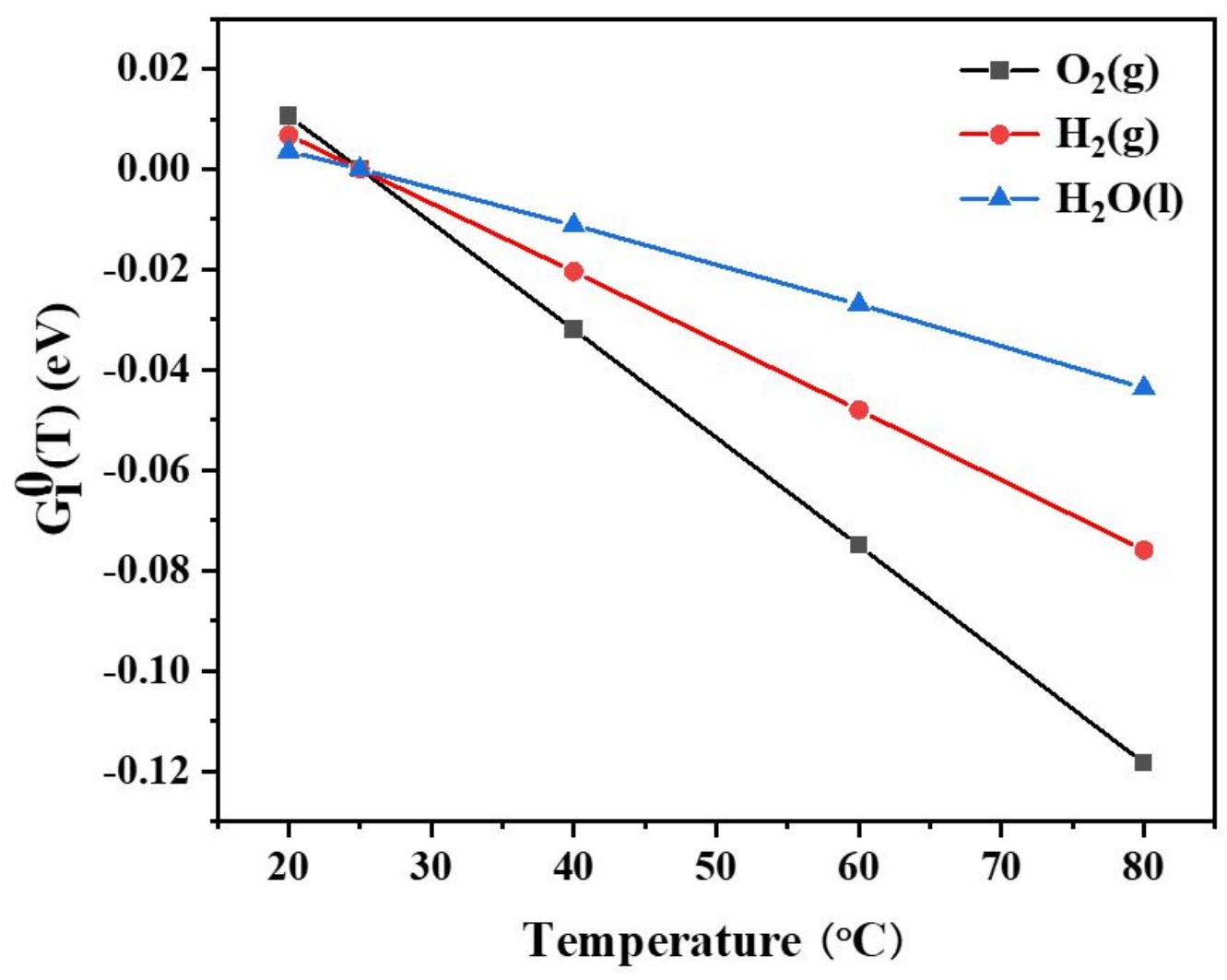

Figure S8. The calculated standard Gibbs free energies $G_{i}^{0}(T)$ of $\mathrm{O}_{2}(\mathrm{~g}), \mathrm{H}_{2}(\mathrm{~g})$ and $\mathrm{H}_{2} \mathrm{O}(\mathrm{l})$ as a function of temperature referenced to their respective values at room temperature $\left(25^{\circ} \mathrm{C}\right)$. 


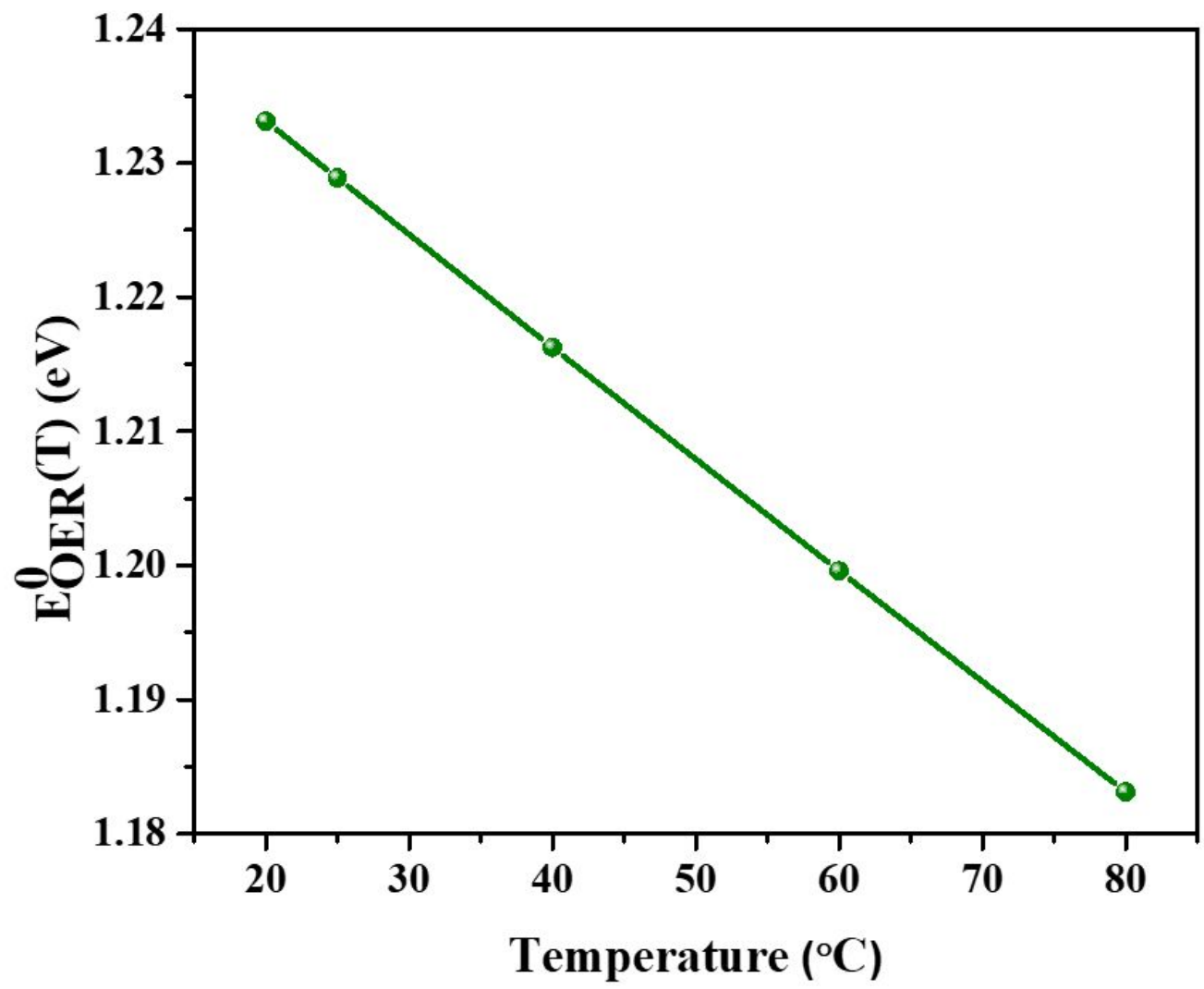

Figure S9. The calculated standard reduction potential of the OER $\left(E_{\mathrm{OER}}^{0}\right)$ measured versus the RHE as a function of temperature. 


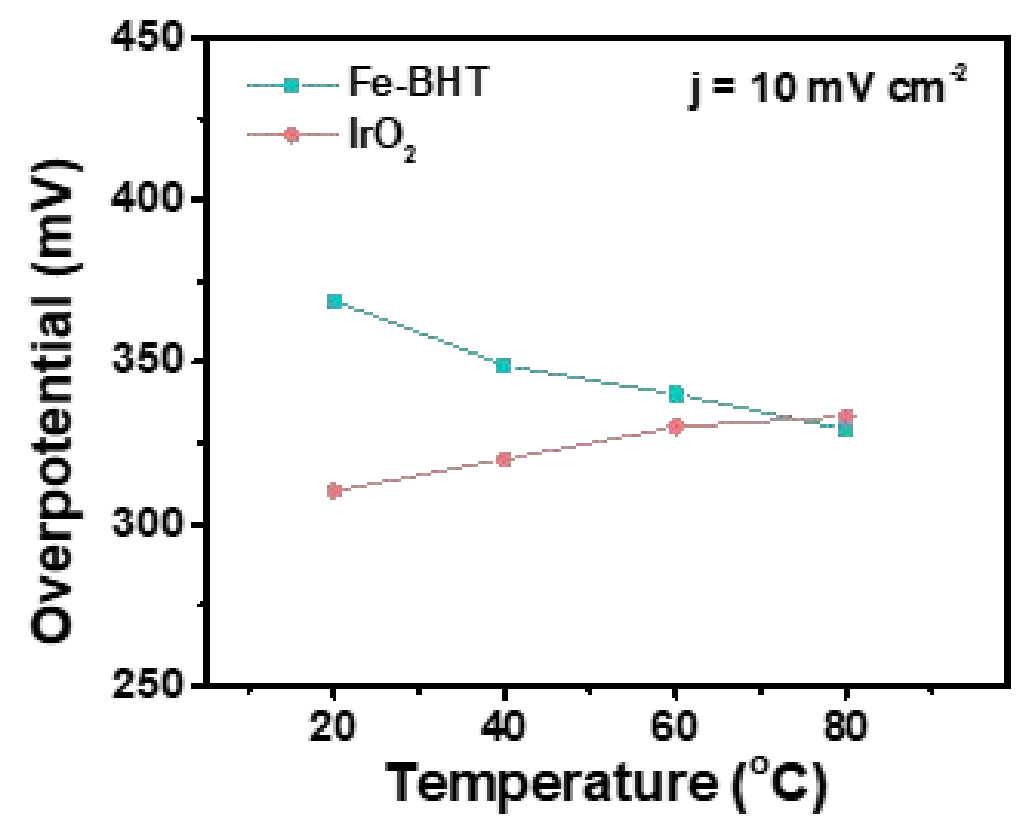

Figure S10. Overpotentials of OER on Fe-BHT and $\mathrm{IrO}_{2}$ as a function of temperature. The standard OER potentials are corrected according to temperature effects shown in Figure S9.

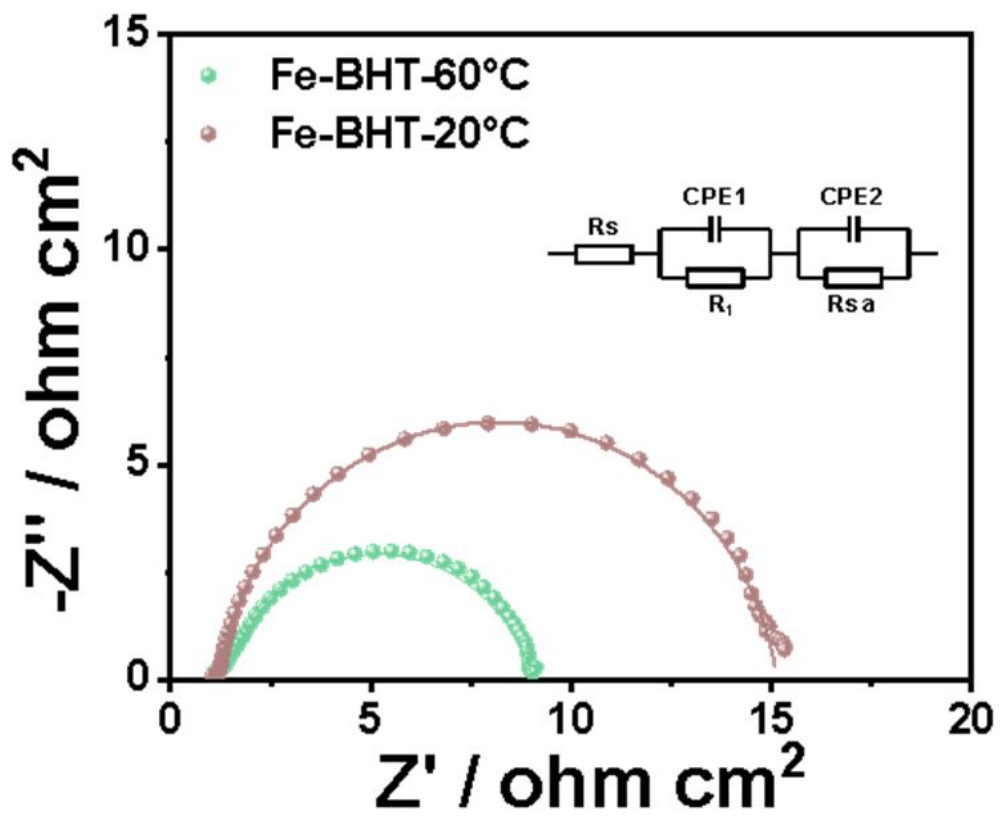


Figure S11. The EIS spectra for Fe-BHT nanocrystals at $20{ }^{\circ} \mathrm{C}$ and $60{ }^{\circ} \mathrm{C}$. Inset is the equivalent circuit diagram. It can be found that at $60{ }^{\circ} \mathrm{C} \mathrm{Fe}-\mathrm{BHT}$ shows smaller Rct value than that at $20{ }^{\circ} \mathrm{C}$. This suggests that the heat treatment can improve the interfacial charge transfer from electrode to electrolyte, which is critical for electrocatalytic OER.

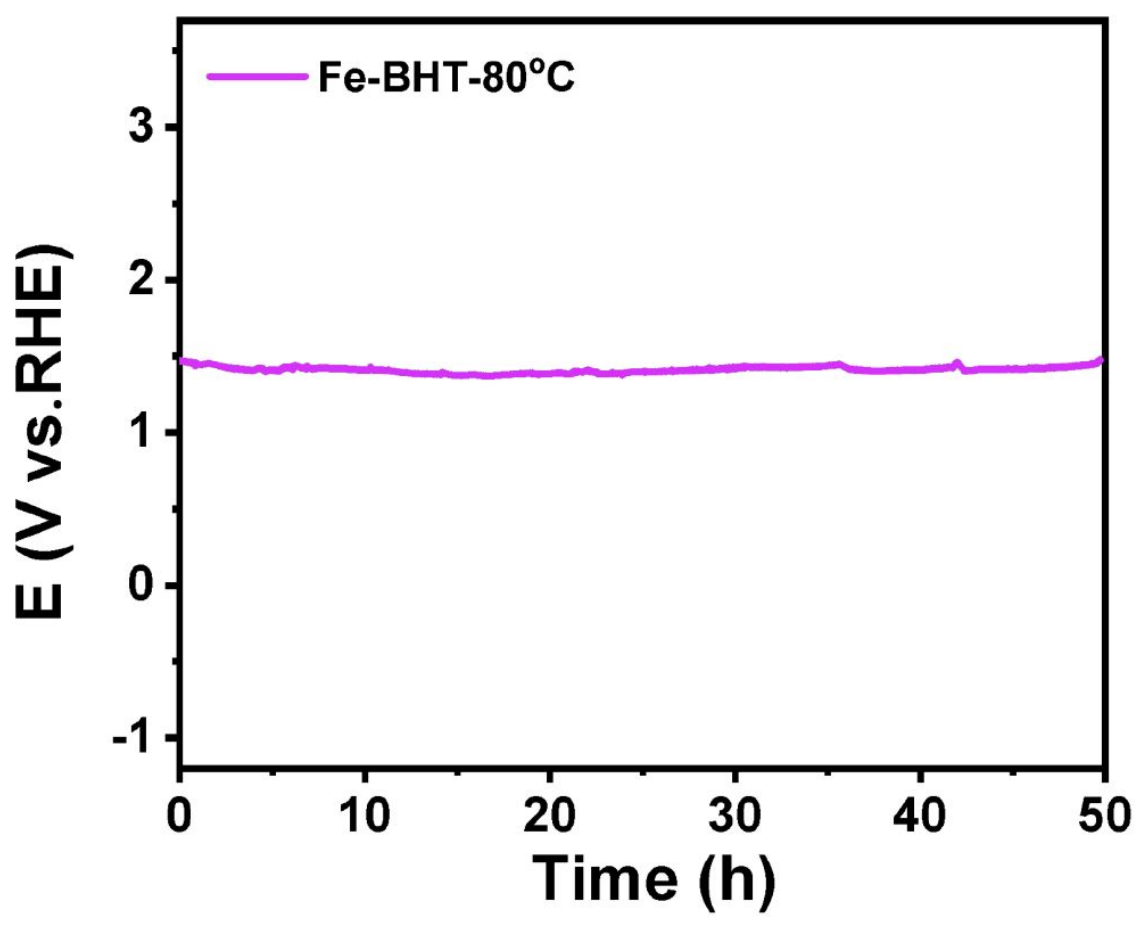

Figure S12. The long-time durability test of Fe-BHT nanocrystals at a stationary current density of $10 \mathrm{~mA} \mathrm{~cm}{ }^{-2}$ at $80{ }^{\circ} \mathrm{C}$ for $50 \mathrm{~h}$ in $1.0 \mathrm{M} \mathrm{KOH}$ solution. 

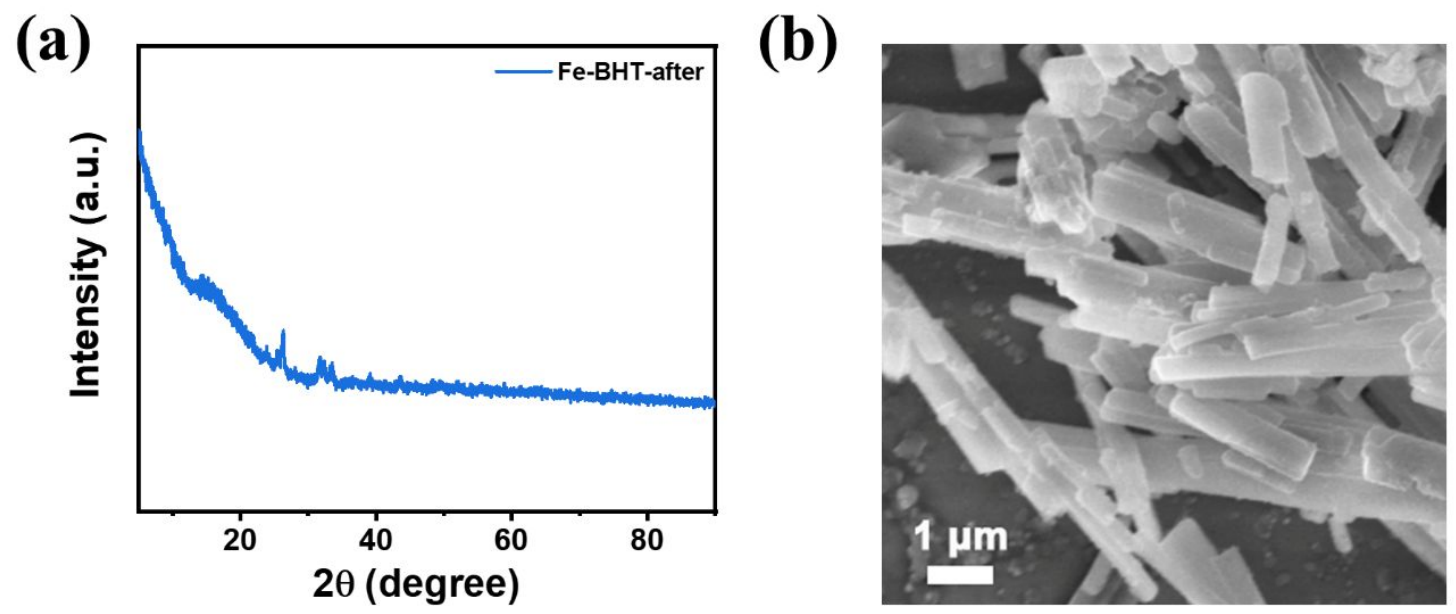

Figure S13. (a) XRD pattern and (b) SEM image after the long-time durability test of Fe-BHT nanocrystals.

\section{REFERENCES}

(1) Kresse, G.; Furthmuller, J. Efficient iterative schemes for ab initio total-energy calculations using a plane-wave basis set. Phys. Rev. B 1996, 54, 11169-11186.

(2) Kresse, G.; Furthmuller, J. Efficiency of ab-initio total energy calculations for metals and semiconductors using a plane-wave basis set. Comput. Mater. Sci. 1996, 6, 15-50.

(3) Blochl, P. E. PROJECTOR AUGMENTED-WAVE METHOD. Phys. Rev. B 1994, 50, 17953-17979. 
(4) Kresse, G.; Joubert, D. From ultrasoft pseudopotentials to the projector augmented-wave method. Phys. Rev. B 1999, 59, 1758-1775.

(5) Perdew, J. P.; Chevary, J. A.; Vosko, S. H.; Jackson, K. A.; Pederson, M. R.; Singh, D. J.;

Fiolhais, C. ATOMS, MOLECULES, SOLIDS, AND SURFACES - APPLICATIONS OF THE GENERALIZED GRADIENT APPROXIMATION FOR EXCHANGE AND CORRELATION.

Phys. Rev. B 1992, 46, 6671-6687.

(6) Perdew, J. P.; Burke, K.; Ernzerhof, M. Generalized gradient approximation made simple.

Phys. Rev. Lett. 1996, 77, 3865-3868.

(7) Grimme, S.; Antony, J.; Ehrlich, S.; Krieg, H. A consistent and accurate ab initio parametrization of density functional dispersion correction (DFT-D) for the 94 elements H-Pu. $J$.

Chem. Phys. 2010, 132, 154104.

(8) Henkelman, G.; Uberuaga, B. P.; Jonsson, H. A climbing image nudged elastic band method for finding saddle points and minimum energy paths. J. Chem. Phys. 2000, 113, 9901-9904. 
(9) Man, I. C.; Su, H. Y.; Calle-Vallejo, F.; Hansen, H. A.; Martinez, J. I.; Inoglu, N. G.; Kitchin,

J.; Jaramillo, T. F.; Norskov, J. K.; Rossmeisl, J. Universality in Oxygen Evolution Electrocatalysis on Oxide Surfaces. ChemCatChem 2011, 3, 1159-1165.

(10) Norskov, J. K.; Rossmeisl, J.; Logadottir, A.; Lindqvist, L.; Kitchin, J. R.; Bligaard, T.;

Jonsson, H. Origin of the overpotential for oxygen reduction at a fuel-cell cathode. J. Phys.

Chem. B 2004, 108, 17886-17892.

(11) Bjork, J. Thermodynamics of an Electrocyclic Ring-Closure Reaction on Au(111). J. Phys. Chem. C2016, 120, 21716-21721.

(12) Rajan, A. G.; Martirez, J. M. P.; Carter, E. A. Coupled Effects of Temperature, Pressure, and $\mathrm{pH}$ on Water Oxidation Thermodynamics and Kinetics. Acs Catalysis 2021, 11, 1130511319.

(13) Chase Jr, M. W. NIST-JANAF thermochemical tables. J. Phys. Chem. Ref. Data, Monograph 1998, 9, 1-1951.

(14) Ives, D. J.; Janz, G. J.; King, C. Reference electrodes: theory and practice. J. Electrochem. Soc. 1961, 108, 246C. 
(15) Kerner, Z.; Balog, J.; Nagy, G. Testing of high temperature reference electrodes for light water reactor applications. Corros. Sci. 2006, 48, 1899-1911. 